\title{
CNC makinelerinin bazı ayarlarının parça işleme süresi ve lif levhanın yüzey pürüzlülüğü üzerine etkileri
}

\author{
Bekir Cihad Bal*
}

$\ddot{\mathbf{O z}}$

CNC (Computer Numerical Control) makineleri farklı üretim endüstrilerinde yıllardır kullanılmaktadır. Bu makineler, çok yüksek hassasiyet, yüksek üretim hızı ve işlemlerin sınırsız tekrarı gibi bazı özelliklere sahiptirler. Bazı önemli ayarlamalar CNC makinelerinin çalıştırılması için yapılmak zorundadır. Bunlar; bıçak motoru hızı, kesme derinliği, bıçak adımı, besleme hızı, güvenli yükseklik, işleme taktiği vs.dir. Bu ayarlamaların, işlenen malzemenin yüzey pürüzlülüğü üzerine ve her bir parçanın işlenme süresi üzerine bir etkisi vardır. Bu çalışmada, orta yoğunlukta lif levhanın yüzey pürüzlülüğü ve işleme süresi üzerine, bıçak adımı ( $\% 20, \% 40, \% 60$ ve $\% 80)$ ve besleme hızı $(1,3,5$ ve $7 \mathrm{~m} / \mathrm{dk})$ ayarlarının etkisi araştırılmıştır. Test örnekleri cep işleme yöntemi ile zig-zag taktiği kullanılarak işlenmiştir. Yüzey pürüzlülük ölçümleri TS 971'e göre yapılmıştır. Ortalama pürüzlülük $(\mathrm{Ra}), 10$ nokta pürüzlülügü $(\mathrm{Rz})$ ve kareler ortalamasının karekökü $(\mathrm{Rq})$ olan 3 pürüzlülük değeri belirlenmiştir. Elde edilen verilere göre; besleme hızı ve bıçak adımı arttıkça, yüzey pürüzlülüğü artmış ve işlem süresi azalmıştır. Ayrıca, yüzey pürüzlülüğü ve işlem süresi üzerine bıçak adımının besleme hızından daha etkili olduğu belirlenmiştir.

Anahtar kelimeler: CNC, lif levha, yüzey pürüzlülük, işlem süresi

\section{The effects of some tool paths adjustments of CNC machines on surface roughness and processing time of fiberboards}

\begin{abstract}
CNC (Computer Numerical Control) machines have been used in different manufacturing industries for years. These machines have some properties such as superior sensitivity, high manufacturing speed, and unlimited repetition of operations. Some important adjustments have to be made to operate of CNC machines. These are spindle speed, cutting depth, step over, feed rate, machine safe height, clearance strategy, and so on. These adjustments have an effect on the surface roughness of the material being processed and on the processing time for each part. In this study, the influence of the step over $(20 \%, 40 \%, 60 \%$ and $80 \%$ ) and feed rate $(1,3,5$ and $7 \mathrm{~m} / \mathrm{min})$ settings on the surface roughness of medium density fiberboard and the processing time were investigated. The test specimens were processed using the raster strategy with the pocket processing method. Surface roughness measurements were made according to TS 971. Three roughness values were determined, with an average roughness $(\mathrm{Ra})$, a 10 point roughness $(\mathrm{Rz})$ and a root mean square average (Rq). According to the obtained data; as the feed rate and the step over are increased, the surface roughness is increased and the processing time is decreased. In addition, it has been determined that the step over is more effective than the feed rate on the surface roughness and the processing time.
\end{abstract}

Keywords: CNC, fiber board, surface roughness, processing time 


\section{Giriș}

CNC tezgâhları öncelikli olarak uçak ve helikopter fabrikalarındaki ihtiyaçları karşılamak için ortaya çıkmıştır. Otomotiv endüstrisinde uygulanması sırasında gelişmiş ve yaygınlaşmıştır. 1946 yılında ilk olarak geliştirilen NC (Numerical Control) kontrollü bir freze tezgâhı olmuştur. Bu tezgâh, delikli şerit kartlarla yönetilmiştir. NC kontrol John T. Parsons adında, Amerikalı bir mühendis tarafından geliştirilmiştir (Oral 2012). Bilgisayar teknolojisindeki gelişmelerle beraber, programların hafızada saklanmaları mümkün olmuş ve sonuç olarak bu gelişmeler CNC kavramının doğmasına öncülük etmiştir (Dinçel 1999). CNC tezgâhların yaygınlaşmaya başlaması ile yeni tezgâh tasarımı ve kullanımı tamamıyla değişmiş, mühendislerle atölye ve fabrika sahiplerine yepyeni olanaklar ortaya çıkmaya başlamıştır (Erer 2000). CNC makinelerinde parça işleme, CAD ve CAM programlarının kullanılması ve bu programlardan elde edilen kodların CNC kontrol ünitesine yüklenmesi ile sağlanmaktadır. CAM yazılımları; parça ve takım geometrisinin tanımlanması, kesici konumlama dosyasının oluşturulması, kesici konumlama dosyasında bulunan verilerin tezgâhta kullanılabilecek duruma dönüştüren son işlemci, takım yolu doğrulama ve simülasyonu ve üretim kontrol araçları gibi fonksiyonları içermektedir (Varol ve ark., 2005).

Günümüzde farklı üretim tiplerinde ve farklı amaçlar için geliştirilmiş çok değişik tipte ve özellikte CNC makineleri bulunmaktadır. $\mathrm{Bu}$ makinelerin istenen işi yapabilmesi için gerekli olan kod dosyasının hazırlanması ve CNC kontrol ünitesine yüklenmesi gerekmektedir. $\mathrm{Bu}$ kod dosyaları hazırlanırken CAM programlarında birçok ayarlama yapılmaktadır. Bunlardan bazıları; bıçak motoru hızı, kesme derinliği, bıçak adımı, besleme hızı, güvenli yükseklik, işleme taktiği, bıçak tipi şeklinde sıralanabilir. $\mathrm{Bu}$ yapılan ayarlamalara göre, işlem gören iş parçasının yüzey pürüzlülüğü ve işlem süresi değişkenlik göstermektedir. Genel bir kural olarak, işlem gören iş parçasının yoğunluğu arttıkça (demir, çelik vs.) besleme hızı, bıçak adımı ve kesme derinliği (veya dalma derinliği) küçük tutulmak zorundadır. Yoğunluğu düşük ve işlenmesi kolay malzemelerde (ahşap malzemeler vs.) ise bu ayarlar büyük tutulmaktadır. Malzeme yoğunluğuna göre bu ayarlamalar değişmektedir.

CNC makineleri için oluşturulan kod dosyalarında yapılan ayarların, malzeme yüzey kalitesi üzerine etkisine ilişkin geçmişte birçok araştırma yapılmıştır. Örneğin, Benardos ve Vosniakos (2003) ve Karagöz (2011) tarafından yapılan derleme çalışmalar bu konuda genel kriterleri ortaya koymuştur. Bu çalışmalarda, pürüzlülük üzerine etkili olan parametreler; kesici takım ile ilgili parametreler, kesme ile ilgili parametreler, işleme ile ilgili parametreler ve işlenen malzeme ile ilgili parametreler şeklinde gruplandırılmıştır. Ahşap esaslı malzemelerin $\mathrm{CNC}$ makinelerinde işlem görmesi esnasında, bazı takım yolu ayarlarının etkileri ile ilgili olarak da bazı çalışmalar yapılmıştır. Örneğin; Ohuchi ve Murase (2001) tarafından yapılan çalışmada, MDF (Medium Density Fiberboard), yonga levha, kontrplak ve masif ahşap (katsura) üzerinde özellikle bıçak motoru hızı ve besleme hızı üzerine bazı denemeler yapılmıştır. MDF ve yonga levhada kesme hatalarının bıçak motoru hızı ve besleme hızından etkilenmediğini belirlemişlerdir. MDF levhaların yüzeylerinin CNC makinelerde işlem görmesi esnasında bazı makine ayarlarının yüzey pürüzlülüğü üzerine etkileri Sütçü ve Karagöz (2012) tarafından incelenmiştir. Çalışma sonunda besleme hızı, bıçak motor hızı, kesme derinliği ve bıçak adımı gibi faktörlerin yüzey pürüzlülüğü üzerine etkileri incelenmiştir. Bu çalışma sonuçlarına göre; bıçak motorunun hızı arttıkça ve besleme hızı, bıçak adımı ve kesme derinliği azaldıkça yüzey pürüzlülüğü azalma göstermiştir. Deus ve ark., (2015) tarafindan da benzer sonuçlar bulunmuştur. MDF yüzeylerin CNC makinelerde işlenmesi esnasında takım yolu ayarlarının yüzey pürüzlülüğü üzerine etkileri Davim ve ark., (2009) tarafından incelenmiştir. Araştırmada, bıçak motoru hızı ve besleme 
hızı faktörlerinin etkisi ölçülmüştür. Elde edilen verilere göre besleme hızı 4 m/dk'ya kadar artırıldığında yüzey pürüzlülüğünün arttığı $4 \mathrm{~m} / \mathrm{dk}$ 'nın üzerine çıktığında ortalama yüzey pürüzlülügünde azalmalar belirlenmiştir. Bıçak motoru hızının artmasıyla genel olarak yüzey pürüzlülügü azalmıştır. Lou ve ark., (1998) tarafından da benzer sonuçlar tespit edilmiştir. Sofuoğlu (2015) tarafından yapılan çalışmada, CNC makineleri ile ahşap panellerin yüzeylerinin işlenmesinde, diğer araştırmalardan farklı olarak, işleme taktiği araştırılmış ve sonuçta spiral taktiğin zig-zag taktiğinden daha iyi sonuç verdiği belirlenmiştir.

Literatürdeki bu çalışmalar incelendiğinde genel olarak yapılan çalışmaların, CNC makinesinin takım yolu ayarlarının işlenen malzemenin yüzey pürüzlülüğg̈ üzerine etkisinin araştırıldığ 1 görülmektedir. Ancak, MDF malzeme üzerinde yapılan çalışmalar içerisinde, CNC makinesinde işlenen MDF parçanın işlem süresi üzerine yapılan bir çalışmaya rastlanmamıştır. $\mathrm{Bu}$ nedenle, bu çalışmada, MDF levhaların CNC makinesi ile işlenmesi esnasında, takım yolu ayarlarının her bir parça için işlem süresi ve $\mathrm{Ra}, \mathrm{Rq}, \mathrm{Rz}$ pürüzlülük değerleri üzerine etkilerinin belirlenmesi amaçlanmıştır.

\section{Materyal ve Metot}

\subsection{Materyal}

Bu çalışmada, deneme materyali olarak, piyasada tek yüz kaplı MDF olarak bilinen ve özellikle bir yüzeyi CNC makinelerinde işlenmek için üretilen MDF levhalar kullanılmıştır. MDF levhalar piyasadan satın alma yöntemi ile tedarik edilmiştir. Temin edilen MDF levhaların ölçüleri 18x2100x2800 mm (kalınlık x genişlik x uzunluk)'dir. Test örneklerinin işlenmesinde HSS (High Speed Steel) çelikten iki kanatlı boşaltma bıçakları kullanılmıştır.

Test örneklerinin yüzey pürüzlülükleri "Diferansiyel Endüktans" prensibi ile çalışan ve Şekil 1'de verilen "Mitutoyo surftest SJ-210" model cihazla yapılmıştır. Yüzey pürüzlülüğü ölçüm cihazı ayarları ve özellikleri; kesme uzunluğu $\lambda c: 2.5 \mathrm{~mm}$, stylus ucu açısı: $60^{\circ}$, sürücü ünite hızı: $0.75 \mathrm{~mm} / \mathrm{sn}$, x ekseni ölçüm aralığı: $12.5 \mathrm{~mm}$, z eksen: $360 \mu \mathrm{m}$ şeklindedir.

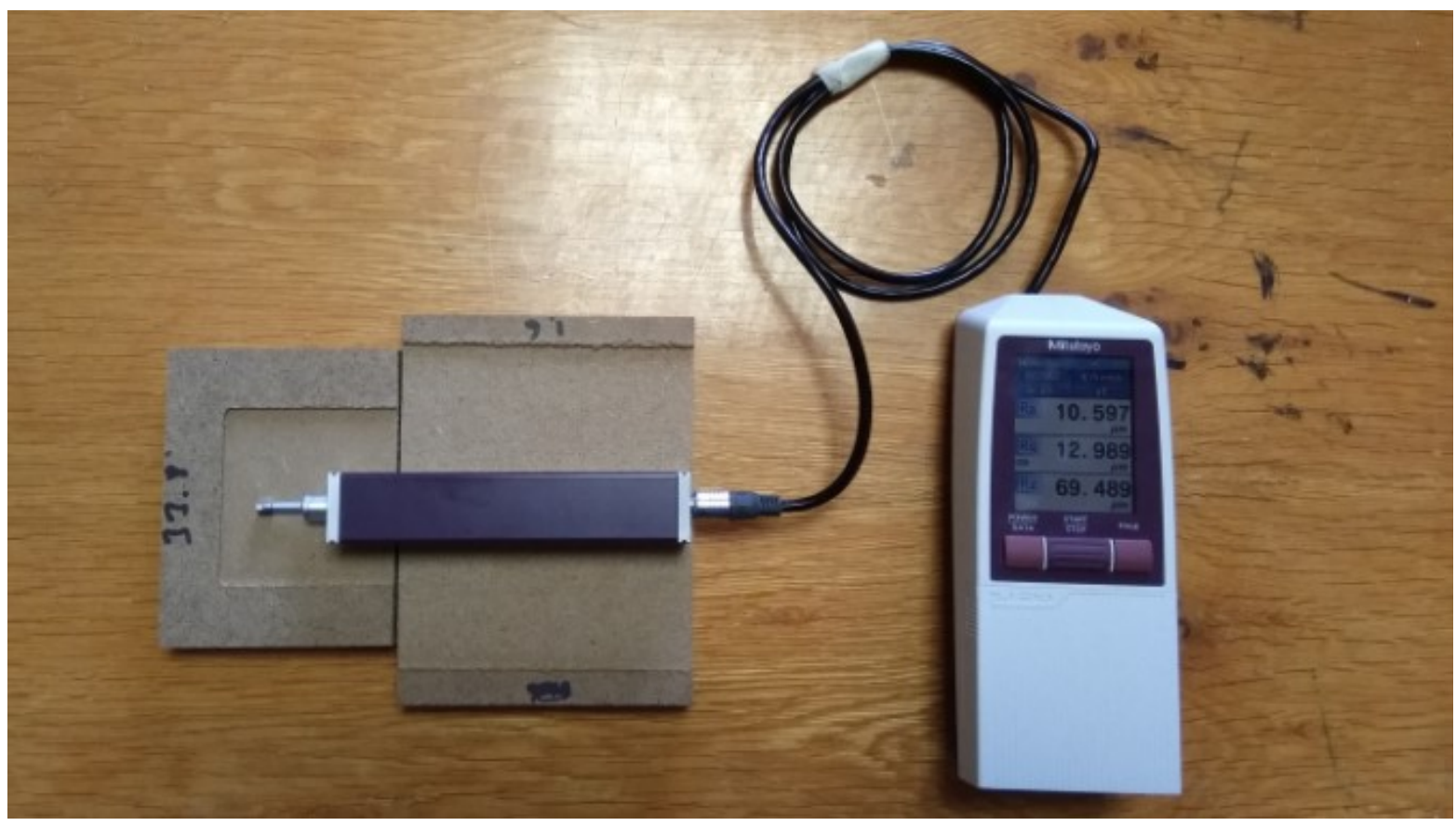

Şekil 1. Pürüzlülük ölçüm cihazı 
Testlerin yapılmasında, özel olarak imal edilmiş, 3 eksenli bir CNC makinesi (CNC router) kullanılmıştır. CNC makinesi özel olarak imal edilmiş bir makinedir (Şekil 2). Makinenin işleme alanı 700x1000x150 mm (x,y,z) ölçülerindedir. Hareket motorları servo motorludur. $\mathrm{X}$ ekseni hareketi ve $\mathrm{Z}$ ekseni hareketi için bir, $\mathrm{Y}$ ekseni hareketi için iki adet servo motoru bulunmaktadır. Bıçak motoru maksimum 18000 d/dk'da çalışabilen 3 fazlı hava soğutmalı Herz marka bir motordur.

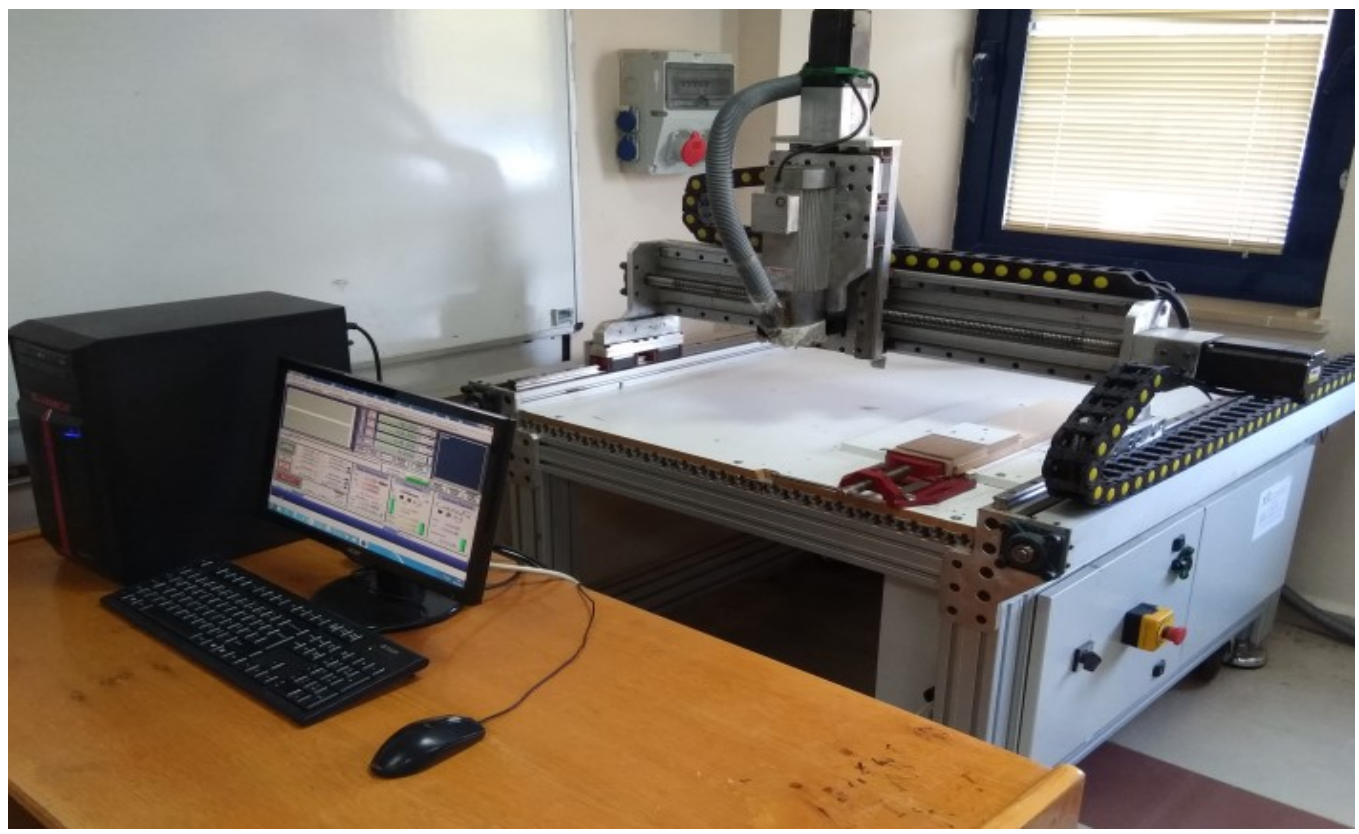

Şekil 2. Testlerin yapıldı̆̆ı CNC makinesi

\subsection{Metot}

Denemelerde MDF test örnekleri 18x120x120 mm (kalınlık x genişlik x uzunluk) ölçülerinde ve her grup için 10 adet test örneği hazırlanmıştır. Denemeler test örneklerinin kaplanmamış yüzeyinde yapılmıştır. Test örneklerinin orta kısmında 100x100 mm kare alan CNC makinesinde boşaltılmıştır. Bu işlem esnasında, işlem süresi Mach3 programından takip edilmiş ve hesaplanmıştır. Pürüzlülük ölçümleri bu kısımda yapılmıştır.

CNC makinesinde test örneklerinin işlem görebilmesi için gerekli kodlar ArtCAM programında oluşturulmuştur. Kod dosyası CNC kontrol programına (Mach3) aktarılmış ve makine bu program ile kontrol edilmiştir. CNC makinesinin biçak motoru devri $8000 \mathrm{~d} / \mathrm{dk}$, besleme hızı 1, 3, 5 ve $7 \mathrm{~m} / \mathrm{dk}$, bıçak adımı $\% 20, \% 40, \% 60$ ve $\% 80$, güvenli $Z$ yüksekliği 10 $\mathrm{mm}$, işleme taktiği zig-zag olarak ayarlanmıştır. Kesme derinliği $2 \mathrm{~mm}$ olarak ayarlanmıştır. $\mathrm{Bu}$ çalışmada, 4 farklı bıçak adımı ve 4 farklı besleme hızı olmak üzere 8 farklı kombinasyonun süre ve pürüzlülük ölçümleri yapılmıştır.

Test örneklerinin rutubet yüzdelerinin belirlenmesinde TS EN 322, yoğunluk miktarlarının belirlenmesinde TS EN 323 ve pürüzlülük değerlerinin belirlenmesinde TS 971 numaralı standartlardan yararlanılmıştır.

Elde edilen veriler Excel programında kaydedilmiş ve SPSS istatistik programında 2 yönlü ANOVA ile değerlendirilmiştir. Aralarında farklılık belirlenen gruplara Duncan testi yapılmıştır. 


\section{Bulgular ve Tartışma}

Yapılan testler sonunda, test örneklerinin yoğunluğu $762 \mathrm{~kg} / \mathrm{m}^{3}$ ve rutubet içeriği $\% 8.2$ olarak belirlenmiştir. Besleme hızı ve bıçak adımı faktörlerinin farklı kombinasyonlarına göre elde edilen pürüzlülük ve işlem süresine ait ortalama ve standart sapma değerleri Çizelge 1'de verilmiştir.

Çizelge 1. Pürüzlülük ve işlem süresine ait veriler

\begin{tabular}{|c|c|c|c|c|c|c|}
\hline BA & $\mathrm{BH}$ & in & $\mathrm{Ra}$ & $\mathrm{Rq}$ & $\mathrm{Rz}$ & Süre \\
\hline$\%$ & $\mathrm{~m} / \mathrm{dk}$ & ID & $\mu \mathrm{m}$ & $\mu \mathrm{m}$ & $\mu \mathrm{m}$ & sn \\
\hline \multirow{8}{*}{20} & \multirow{2}{*}{1} & $\mathrm{x}$ & 7.37 & 9.27 & 50.27 & 596 \\
\hline & & SS & 0.69 & 0.76 & 3.75 & 0.63 \\
\hline & \multirow{2}{*}{3} & $\mathrm{x}$ & 8.33 & 10.59 & 57.75 & 221 \\
\hline & & SS & 0.54 & 0.57 & 2.82 & 0.53 \\
\hline & \multirow{2}{*}{5} & $x$ & 9.28 & 11.68 & 61.63 & 133 \\
\hline & & SS & 0.72 & 0.97 & 5.34 & 0.92 \\
\hline & \multirow{2}{*}{7} & $\mathrm{x}$ & 9.03 & 11.40 & 61.53 & 101 \\
\hline & & ss & 0.41 & 0.43 & 2.70 & 0.57 \\
\hline \multirow{8}{*}{40} & \multirow{2}{*}{1} & $\mathrm{x}$ & 8.97 & 11.54 & 65.54 & 329 \\
\hline & & SS & 0.72 & 1.03 & 5.77 & 0.53 \\
\hline & \multirow{2}{*}{3} & $\mathrm{x}$ & 8.99 & 11.43 & 62.15 & 121 \\
\hline & & ss & 0.61 & 0.71 & 3.65 & 0.53 \\
\hline & \multirow{2}{*}{5} & $\mathrm{x}$ & 8.89 & 11.29 & 61.64 & 80 \\
\hline & & ss & 0.49 & 0.60 & 3.88 & 0.52 \\
\hline & \multirow{2}{*}{7} & $\mathrm{x}$ & 9.25 & 11.73 & 63.41 & 62 \\
\hline & & SS & 1.01 & 1.23 & 5.94 & 0.48 \\
\hline \multirow{8}{*}{60} & \multirow{2}{*}{1} & $\mathrm{x}$ & 10.08 & 13.00 & 70.99 & 234 \\
\hline & & SS & 0.68 & 1.01 & 6.06 & 0.7 \\
\hline & \multirow{2}{*}{3} & $\mathrm{x}$ & 9.93 & 12.80 & 68.58 & 89 \\
\hline & & SS & 0.71 & 0.84 & 5.11 & 0.52 \\
\hline & \multirow{2}{*}{5} & $\mathrm{x}$ & 9.94 & 12.71 & 68.25 & 61 \\
\hline & & SS & 0.57 & 0.69 & 4.86 & 0.53 \\
\hline & \multirow{2}{*}{7} & $\mathrm{x}$ & 10.28 & 13.20 & 70.70 & 48 \\
\hline & & ss & 0.54 & 0.55 & 2.40 & 0.63 \\
\hline \multirow{8}{*}{80} & \multirow{2}{*}{1} & $\mathrm{x}$ & 11.59 & 14.78 & 75.60 & 191 \\
\hline & & SS & 0.81 & 0.98 & 4.53 & 0.53 \\
\hline & \multirow{2}{*}{3} & $\mathrm{x}$ & 11.86 & 15.01 & 74.54 & 74 \\
\hline & & SS & 1.14 & 1.16 & 5.87 & 0.95 \\
\hline & \multirow{2}{*}{5} & $\mathrm{x}$ & 11.12 & 14.30 & 72.19 & 51 \\
\hline & & ss & 0.52 & 0.70 & 4.26 & 0.57 \\
\hline & \multirow{2}{*}{7} & $\mathrm{x}$ & 11.64 & 14.95 & 74.79 & 42 \\
\hline & & SS & 1.14 & 1.54 & 9.08 & 0.52 \\
\hline
\end{tabular}

BA: bıçak adımı, BH: besleme hızı, İD: istatistik değerler, x: aritmetik ortalama, ss: standart sapma, Ra ve süre değerleri Bal (2017)'den alınmıştır. 
Çizelge 1 incelendiğinde, genel olarak bıçak adımı arttıkça pürüzlülük değerlerinin arttığı görülmektedir. En düşük pürüzlülük değerleri $\% 20$ bıçak adımında ve $1 \mathrm{~m} / \mathrm{dk}$ besleme hızında elde edilmiştir. Bıçak adımı arttıkça pürüzlülüğün genel olarak doğrusal bir şekilde arttığ görülmektedir. En büyük pürüzlülük değeri ise $\% 80$ bıçak adımında elde edilmiştir. Ancak besleme hızları arasındaki farklar incelendiğinde besleme hızı ile pürüzlülük değeri arasındaki ilişkinin doğrusal olmadığı, değişken olduğu görülmektedir. Çizelgede verilen işlem süresine ait veriler incelendiğinde ise, tüm gruplarda bıçak adımı ve besleme hızı artığında işlem süresinin azaldığı görülmektedir. En küçük işlem süresi 42 sn olarak \%80 bıçak adımında ve $7 \mathrm{~m} / \mathrm{dk}$ besleme hızında elde edilmiştir. En büyük işlem süresi ise, $596 \mathrm{sn}$ olarak \%20 bıçak adımında ve $1 \mathrm{~m} / \mathrm{dk}$ besleme hızında elde edilmiştir.

Bıçak adımı ve besleme hızı faktörlerinin $\mathrm{Ra}, \mathrm{Rq}$ ve $\mathrm{Rz}$ pürüzlülük değerleri üzerine etkisine ilişkin iki yönlü ANOVA testi sonuçları Çizelge 2'de verilmiştir. Çizelge incelendiğinde bıçak adımı ve besleme hızının ve bu iki faktörün etkileşiminin $\mathrm{Ra}$ ve $\mathrm{Rq}$ pürüzlülük üzerine etkisinin istatistiksel olarak önemli (besleme hızının pürüzlülük üzeri etkisi $\mathrm{P}<0.05$ diğerleri $\mathrm{P}<0.001)$ olduğu görülmektedir. Rz değerinde ise bıçak adımı çok ileri düzeyde önemli $(\mathrm{P}<0.001)$ besleme hızı ise önemsiz $(\mathrm{P}>0.05)$ olarak belirlenmiştir. Çizelgede verilen etki boyutu (PES) değerlerine bakarak hangi faktörün etkisinin daha büyük olduğu görülebilmektedir. Buna göre, Ra pürüzlülük değeri üzerine bıçak adımının etkisi (0.741), besleme hızının (0.075) etkisinden ve ikili etkileşiminin etkisinden (0.211) daha büyüktür. Çizelge 2'de verilen $\mathrm{R}^{2}$ belirtme kat sayısına göre (0.76); Ra pürüzlülük değerini etkileyen faktörlerin \%76'sı bıçak adımı ve besleme hızıdır. Diğer faktörlerin etkisi \%24'dür. Rq ve $\mathrm{Rz}$ pürüzlülük değerlerine ait $\mathrm{R}^{2}$ belirtme kat sayıları ise sırasıyla 0.78 ve 0.67 olarak belirlenmiştir.

Çizelge 2. Bıçak adımı ve besleme hızı faktörlerinin pürüzlülük üzerine etkisini gösteren iki yönlü ANOVA testi sonuçları

\begin{tabular}{|c|c|c|c|c|c|c|c|}
\hline \multirow{5}{*}{$\mathrm{Ra}$} & $\begin{array}{c}\text { Varyansın } \\
\text { Kaynağı }\end{array}$ & $\begin{array}{l}\text { Kareler } \\
\text { toplamı }\end{array}$ & $\mathrm{SD}$ & $\begin{array}{c}\text { Kareler } \\
\text { Ortalamas1 } \\
\end{array}$ & F Oranı & $\begin{array}{l}\text { Önem } \\
\text { düzeyi }\end{array}$ & $\begin{array}{c}\text { Etki boyutu } \\
\text { (PES) }\end{array}$ \\
\hline & $\mathrm{BA}$ & 212.698 & 3 & 70.899 & 137.148 & 0.000 & 0.741 \\
\hline & $\mathrm{BH}$ & 6.060 & 3 & 2.020 & 3.908 & 0.010 & 0.075 \\
\hline & $\mathrm{BA} * \mathrm{BH}$ & 19.870 & 9 & 2.208 & 4.271 & 0.000 & 0.211 \\
\hline & $\mathrm{R}^{2}=0,76$ & & & & & & \\
\hline & & & & & & & \\
\hline \multirow{5}{*}{$\mathrm{Rq}$} & $\begin{array}{c}\text { Varyansın } \\
\text { Kaynağı }\end{array}$ & $\begin{array}{l}\text { Kareler } \\
\text { toplamı }\end{array}$ & SD & $\begin{array}{c}\text { Kareler } \\
\text { Ortalamas1 } \\
\end{array}$ & F Oranı & $\begin{array}{l}\text { Önem } \\
\text { düzeyi }\end{array}$ & $\begin{array}{c}\text { Etki boyutu } \\
\text { (PES) }\end{array}$ \\
\hline & BA & 376.65 & 3 & 125.55 & 153.35 & 0.000 & 0.762 \\
\hline & $\mathrm{BH}$ & 8.99 & 3 & 3.00 & 3.66 & 0.014 & 0.071 \\
\hline & $\mathrm{BA} * \mathrm{BH}$ & 31.59 & 9 & 3.51 & 4.29 & 0.000 & 0.211 \\
\hline & $\mathrm{R}^{2}=0,78$ & & & & & & \\
\hline & & & & & & & \\
\hline \multirow{5}{*}{$\mathrm{Rz}$} & $\begin{array}{c}\text { Varyansın } \\
\text { Kaynağ }\end{array}$ & $\begin{array}{l}\text { Kareler } \\
\text { toplamı }\end{array}$ & SD & $\begin{array}{c}\text { Kareler } \\
\text { Ortalaması } \\
\end{array}$ & F Oranı & $\begin{array}{l}\text { Önem } \\
\text { düzeyi }\end{array}$ & $\begin{array}{c}\text { Etki boyutu } \\
(\text { PES })\end{array}$ \\
\hline & BA & 6270.57 & 3 & 2090.19 & 83.07 & 0.000 & 0.634 \\
\hline & $\mathrm{BH}$ & 104.51 & 3 & 34.84 & 1.38 & 0.250 & 0.028 \\
\hline & $\mathrm{BA} * \mathrm{BH}$ & 964.51 & 9 & 107.17 & 4.26 & 0.000 & 0.210 \\
\hline & $\mathrm{R}^{2}=0,67$ & & & & & & \\
\hline
\end{tabular}

BA bıçak adımı, BH: besleme hızı, SD: serbestlik derecesi 
Bıçak adımı ve besleme hızı faktörlerinin işlem süresi üzerine etkisine ilişkin iki yönlü ANOVA testi sonuçları Çizelge 3'de verilmiştir. Çizelge incelendiğinde, her iki faktörün ve ayrıca bu iki faktörün etkileşiminin işlem süresi üzerine etkisi çok ileri düzeyde önemli $(\mathrm{P}<$ 0.001) bulunmuştur. Bıçak adımı, besleme hızının ve bu ikili etkileşiminin işlem süresi üzerine etkisinde PES değerlerine (her üç faktörde 1 olarak hesaplanmıştır) göre fark bulunmamaktadır. İşlem süresi ANOVA testi sonunda elde dilen $\mathrm{R}^{2}$ belirtme katsayısına göre işlem süresini etkileyen bıçak adımı ve besleme hızının etkisi \%100’dür.

Çizelge 3. Bıçak adımı ve besleme hızı faktörlerinin işlem süresine etkisini gösteren iki yönlü ANOVA testi sonuçları

\begin{tabular}{|c|c|c|c|c|c|c|}
\hline $\begin{array}{c}\text { Varyansin } \\
\text { Kaynağ } 1\end{array}$ & $\begin{array}{c}\text { Kareler } \\
\text { toplam1 }\end{array}$ & SD & $\begin{array}{c}\text { Kareler } \\
\text { Ortalamas1 }\end{array}$ & F Oran1 & $\begin{array}{c}\text { Önem } \\
\text { düzeyi }\end{array}$ & $\begin{array}{c}\text { Etki boyutu } \\
\text { (PES) }\end{array}$ \\
\hline $\mathrm{BA}$ & 725449.67 & 3 & 241816.56 & 634272.93 & 0.000 & 1.000 \\
\hline $\mathrm{BH}$ & 1918088.82 & 3 & 639362.94 & 1677017.55 & 0.000 & 1.000 \\
\hline $\mathrm{BA} * \mathrm{BH}$ & 457088.31 & 9 & 50787.59 & 133213.35 & 0.000 & 1.000 \\
\hline $\mathrm{R}^{2}=1$ & \multicolumn{7}{|l}{}
\end{tabular}

Bıçak adımı ve besleme hızı faktörlerinin ortalamalarının pürüzlülük değeri üzerine etkisine ilişkin Duncan testi sonuçları Çizelge 4'de verilmiştir.

Çizelge 4. Bıçak adımı ve besleme hızı faktörlerinin $\mathrm{Ra}, \mathrm{Rq}$ ve $\mathrm{Rz}$ pürüzlülük değerleri üzerine etkisini gösteren Duncan testi sonuçları

\begin{tabular}{|c|c|c|c|c|c|}
\hline \multicolumn{3}{|c|}{ Bicak Adımı } & \multicolumn{3}{|c|}{ Besleme Hizı } \\
\hline $\begin{array}{c}\text { Bıçak } \\
\text { adımı (\%) }\end{array}$ & $\begin{array}{l}\text { Örnek } \\
\text { say1s1 }\end{array}$ & $\begin{array}{l}\text { Ortalama } \\
\operatorname{Ra}(\mu \mathrm{m})\end{array}$ & $\begin{array}{c}\text { Besleme } \\
\text { h1z1 (m/dk) }\end{array}$ & $\begin{array}{l}\text { Örnek } \\
\text { say1s1 }\end{array}$ & $\begin{array}{l}\text { Ortalama } \\
\operatorname{Ra}(\mu \mathrm{m})\end{array}$ \\
\hline 20 & 40 & $8.5 \mathrm{~A}$ & 1 & 40 & $9.5 \mathrm{~A}$ \\
\hline 40 & 40 & $9.0 \mathrm{~B}$ & 3 & 40 & $9.7 \mathrm{AB}$ \\
\hline 60 & 40 & $10.0 \mathrm{C}$ & 5 & 40 & $9.8 \mathrm{AB}$ \\
\hline 80 & 40 & $11.5 \mathrm{D}$ & 7 & 40 & $10.0 \mathrm{~B}$ \\
\hline \multicolumn{3}{|c|}{ Bıçak Adımı } & \multicolumn{3}{|c|}{ Besleme Hızı } \\
\hline $\begin{array}{c}\text { Bıçak } \\
\text { adımı (\%) }\end{array}$ & $\begin{array}{l}\text { Örnek } \\
\text { sayis1 }\end{array}$ & $\begin{array}{l}\text { Ortalama } \\
\mathrm{Rq}(\mu \mathrm{m})\end{array}$ & $\begin{array}{c}\text { Besleme } \\
\text { h1z1 (m/dk) }\end{array}$ & $\begin{array}{l}\text { Örnek } \\
\text { say1s1 }\end{array}$ & $\begin{array}{c}\text { Ortalama } \\
\mathrm{Rq}(\mu \mathrm{m})\end{array}$ \\
\hline 20 & 40 & $10.7 \mathrm{~A}$ & 1 & 40 & $12.1 \mathrm{~A}$ \\
\hline 40 & 40 & $11.5 \mathrm{~B}$ & 3 & 40 & $12.4 \mathrm{AB}$ \\
\hline 60 & 40 & $12.9 \mathrm{C}$ & 5 & 40 & $12.5 \mathrm{AB}$ \\
\hline 80 & 40 & $14.7 \mathrm{D}$ & 7 & 40 & $12.8 \mathrm{~B}$ \\
\hline \multicolumn{3}{|c|}{ Bıçak Adımı } & \multicolumn{3}{|c|}{ Besleme Hizı } \\
\hline $\begin{array}{c}\text { Bıçak } \\
\text { adımı (\%) }\end{array}$ & $\begin{array}{l}\text { Örnek } \\
\text { sayıs1 }\end{array}$ & $\begin{array}{l}\text { Ortalama } \\
\mathrm{Rz}(\mu \mathrm{m})\end{array}$ & $\begin{array}{c}\text { Besleme } \\
\text { h1z1 }(\mathrm{m} / \mathrm{dk})\end{array}$ & $\begin{array}{l}\text { Örnek } \\
\text { sayıs1 }\end{array}$ & $\begin{array}{l}\text { Ortalama } \\
\operatorname{Rz}(\mu \mathrm{m})\end{array}$ \\
\hline 20 & 40 & $57.8 \mathrm{~A}$ & 1 & 40 & $65.0 \mathrm{~A}$ \\
\hline 40 & 40 & $63.2 \mathrm{~B}$ & 3 & 40 & $65.7 \mathrm{~A}$ \\
\hline 60 & 40 & $69.6 \mathrm{C}$ & 5 & 40 & $65.9 \mathrm{~A}$ \\
\hline 80 & 40 & $74.2 \mathrm{D}$ & 7 & 40 & $67.6 \mathrm{~A}$ \\
\hline
\end{tabular}


Çizelgede verilen sonuçlar incelendiğinde bıçak adımı ve besleme hızı arttıkça pürüzlülük değerinin arttığı, ancak bıçak adımı grupları arasındaki farkın daha belirgin olduğu görülmektedir. $\mathrm{Bu}$ konuda yapılan önceki çalışmalarda benzer sonuçlar elde edilmiştir. Örneğin; Sütçü ve Karagöz (2012)'e göre besleme hızı ve bıçak adımı azaldıkça yüzey pürüzlülügü azalma göstermiştir. Deus ve ark. (2015) tarafindan da benzer sonuçlar bulunmuştur. Ancak, ahşap esaslı levhalarla yapılan bazı çalışmalarda besleme hızı ve bıçak adımının yüzey pürüzlülüğü üzerine etkisinin önemsiz olduğu (Sütçü, 2013) diğer bir çalışmada ise önemli olduğu (Sütçü ve Karagöz 2013) belirlenmiştir. Besleme hızının artması ile pürüzlülük değerlerinin de arttığg Davim ve ark., (2009) tarafından ve ayrıca Koç ve ark., (2017) tarafından ahşap esaslı malzemeler üzerine yapılan çalışmada ortaya konmuştur. Sonuçlar arasındaki farkların, seçilen bıçak adımı ve besleme hızı grupları arasındaki büyüklükten kaynaklandığı düşünülmektedir.

Bıçak adımı ve besleme hızı faktörlerinin işlem süresi üzerine etkisine ilişkin Duncan testi sonuçları Çizelge 5'de verilmiştir. Bu sonuçlara göre; bıçak adımı ve besleme hızı arttıkça işlem süresi önemli seviyede azalmaktadır.

Çizelge 5. Bıçak adımı ve besleme hızı faktörlerinin süre üzerine etkisine ilişkin Duncan testi

\begin{tabular}{|c|c|c|c|c|c|}
\hline \multicolumn{3}{|c|}{ Bıçak Adımı } & \multicolumn{3}{|c|}{ Besleme Hizı } \\
\hline $\begin{array}{c}\text { Bıçak } \\
\text { adımı (\%) }\end{array}$ & $\begin{array}{l}\text { Örnek } \\
\text { sayıs1 }\end{array}$ & $\begin{array}{l}\text { Süre } \\
\text { (sn) }\end{array}$ & $\begin{array}{c}\text { Besleme } \\
\text { hızı }(\mathrm{m} / \mathrm{dk})\end{array}$ & $\begin{array}{l}\text { Örnek } \\
\text { sayıs1 }\end{array}$ & $\begin{array}{l}\text { Süre } \\
(\mathrm{sn})\end{array}$ \\
\hline 80 & 40 & $89.4 \mathrm{~A}$ & 7 & 40 & $63.0 \mathrm{~A}$ \\
\hline 60 & 40 & $107.8 \mathrm{~B}$ & 5 & 40 & $81.1 \mathrm{~B}$ \\
\hline 40 & 40 & $147.5 \mathrm{C}$ & 3 & 40 & $125.9 \mathrm{C}$ \\
\hline 20 & 40 & $262.6 \mathrm{D}$ & 1 & 40 & $337.3 \mathrm{D}$ \\
\hline
\end{tabular}

Şekil 3'de farklı bıçak adımlarında işlem gören test örneklerine ait fotoğraf görülmektedir. Fotoğraf incelendiğinde $\% 60$ ve $\% 80$ bıçak adımı ile işlem gören test örneklerinde çıplak gözle rahatlıkla görülebilecek düzeyde bıçak izi ve işlenen alanın kenarlarında kırıklar olduğu görülmektedir. Bu nedenle $\% 60$ ve $\% 80$ bıçak adımlarının test örneklerinde yapılan görsel muayene sonunda bıçak adımlarından kaynaklanan dalgalılıkların rahatlıkla görüldüğü, bunun bir yüzey sorunu olduğu söylenebilir.

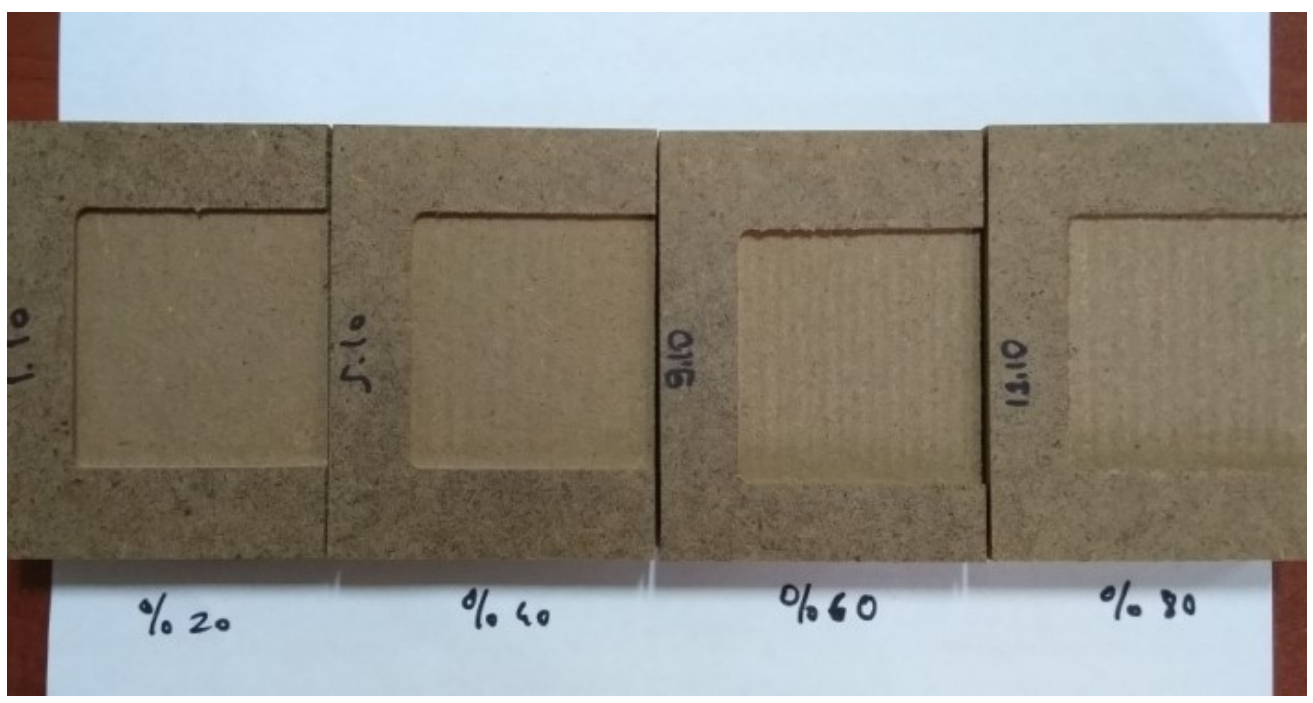

Şekil 3. Farklı bıçak adımlarında işlem gören test örnekleri (Bal, 2017) 
Çizelge 4 ve 5'de verilen sonuçlara göre genel olarak bıçak adımı ve besleme hızı arttıkça yüzey pürüzlülüğünün arttığı ve işlem süresinin azaldığı görülmektedir. Endüstriyel uygulamalarda, MDF levhaların yüzeylerinin CNC makineleri ile işlenmesinde kesin bir şekilde her işletme tarafından uygulanan takım yolu ayarları bulunmamaktadır. İşletmelerde genel olarak yüzey pürüzlülüğ̈̈ gözle muayene ile yapılmakta ve ona göre takım yolu ayarlaması yapılmaktadır. CNC operatörleri parça başına işlem süresi ve yüzey pürüzlülüğü faktörlerine göre yaklaşık bir ayar kullanmaktadır. Yeterli bir yüzey pürüzlüğü ve hızlı bir işlem süresi işletmeler için tercih edilecek bir seçenektir. Bunu belirlemek için ise, bu çalışmada elde edilen pürüzlülük ve işlem süresi sonuçlarına göre; $\% 60$ ve $\% 80$ bıçak adımında ve $7 \mathrm{~m} / \mathrm{dk}$ besleme hızında pürüzlülük ve dalgalılık çok yüksektir. \%20 bıçak adımında ve $1 \mathrm{~m} / \mathrm{dk}$ besleme hızında ise işlem süresi çok uzundur. $\mathrm{Bu}$ nedenle $10 \mu \mathrm{m}$ pürüzlülügün altında değer veren takım yolu ayarları olarak en uygun bıçak adımı \%40-50 ve besleme hızının 3 veya $5 \mathrm{~m} / \mathrm{dk}$ olduğu söylenebilir.

\section{Sonuçlar ve Öneriler}

$\mathrm{Bu}$ çalışmada, CNC makinesinde işlem gören MDF levhaların yüzey pürüzlülükleri ve işlem süresi üzerine bıçak adımı ve besleme hızı faktörlerinin etkisi belirlenmiştir. Elde edilen verilere göre;

- Bıçak adımı ve besleme hızı azaldıkça yüzey pürüzlülüğü azalmakta ve daha düzgün bir yüzey elde edilmektedir. Bıçak adımının pürüzlülük üzerine etkisi besleme hizından fazladir.

- Bıçak adımı ve besleme hızı arttıkça parça başına işlem süresi azalmaktadır. Her iki faktörün işlem süresi üzerine etkisi aynıdır.

- Çalışma sonunda, en uygun biçak adımı \%40-50 ve besleme hızının 3-5 m/dk olduğu söylenebilir.

\section{Teşekkür}

Bu çalışmada sunulan verilerin bir kısmı, TÜBİTAK tarafından desteklenen 215 O 899 numaralı projeden elde edilmiştir. Bu desteğinden dolayı TÜBİTAK'a teşekkür ediyoruz. Bu çalışmada sunulan verilerin bir kısmı, Osmaniye'de yapılan IAREC 2018 kongresinde poster bildiri olarak sunulmuştur.

\section{Kaynaklar}

Bal BC, (2017), Effect of Step Over and Feed Rate Settings of CNC machines on surface roughness and processing time of MDF boards, The 1st International Advanced Research and Engineering Congress, 16-18.11.2017, Proceedings book, P:844-850.

Benardos, PG., and Vosniakos, G. C., (2003), Predicting surface roughness in machining: a review. International journal of machine tools and manufacture, 43(8), 833-844.

Davim, J. P., Clemente, V. C., and Silva, S., (2009), Surface roughness aspects in milling MDF (medium density fibre board). The International Journal of Advanced Manufacturing Technology, 2009, 40(1-2), 49-55.

De Deus, P. R., de Sampaio Alves, M. C., and Vieira, F. H. A., (2015), The quality of MDF work pieces machined in CNC milling machine in cutting speeds, feed rate, and depth of cut, Meccanica, 50(12), 2899-2906. 
Dinçel, M. (1999), CNC takım tezgâhları, Trakya Üniversitesi, Tekirdağ Ziraat Fakültesi Tarım Makineleri Bölümü Lisans Bitirme Tezi.

Erer, H., (2000), CNC takım tezgâhlarının gelişimi, http://www.turkcadcam.net/rapor/cncttg/index.html, son erişim tarihi: 18.06.2018.

Karagöz, Ü. (2011), CNC ile işlemede ahşap malzemenin yüzey kalitesini etkileyen faktörler, Kastamonu Üniversitesi Orman Fakültesi Dergisi, 11(1), 18-26.

Koc, K. H., Erdinler, E. S., Hazir, E., and Öztürk, E., (2017), Effect of CNC application parameters on wooden surface quality, Measurement, 107 (2017), 12-18.

Lou, M. S., Chen, J. C., and Li, C. M. (1998), Surface roughness prediction technique for CNC end-milling, Journal of industrial technology, 15(1), 1-6.

Ohuchi, T., and Murase, Y., (2001), Milling of wood and wood-based materials with a computerized numerically controlled router $\mathrm{I}$, on the machining accuracy for grooving, Mokuzai Gakkaishi, 47(3), 212-217.

Oral A., (2012), CNC takım Tezgahları ve CNC programlama ders notları, Balıkesir Üniversitesi, Makine mühendisliği Bölümü, Basılmamış Ders Notları

Sofuoglu, S. D. (2015), Determination of optimal machining parameters of massive wooden edge-glued panels made of European larch (Larix decidua Mill.) using Taguchi Design Method, BioResources, 10(4), 7772-7781.

Sütcü, A., and Karagöz, Ü. (2012), Effect of machining parameters on surface quality after face milling of MDF, Wood Research, 57(2), 231-240.

Sütçü, A. (2013), Investigation of parameters affecting surface roughness in CNC routing operation on wooden EGP, BioResources, 8(1), 795-805.

Sütçü, A., and Karagöz, Ü. (2013), The influence of process parameters on the surface roughness in aesthetic machining of wooden edge-glued panels (EGPs), BioResources, 8(4), 5435-5448.

TS EN 322, Ahşap esaslı levhalar-rutubet miktarının tayini, TSE, Ankara,1999.

TS EN 323, Ahşap esaslı levhalar-birim hacim ağırlığının tayini, TSE, Ankara,1999.

TS 971, Yüzey pürüzlülüğ̈̈-parametreler ve pürüzlülük tespiti kuralları, TSE, Ankara,1999.

Varol, R., Yalçın, B., ve Yılmaz, N. (2005), Bilgisayar destekli imalatta (CAM), cam programı kullanılarak parça imalatının gerçekleştirilmesi. Makine Teknolojileri Elektronik Dergisi, 3, 47-57. 